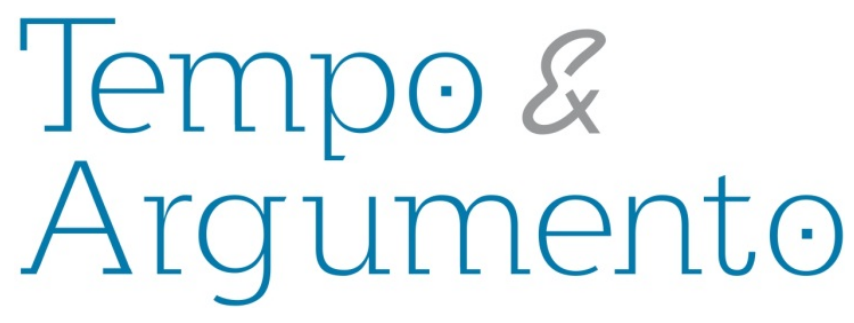

\title{
Aproximações entre história pública e história oral: o caso do Laboratório de História Oral da Univille ${ }^{1}$
}

\begin{abstract}
Resumo
Neste artigo, construímos uma aproximação teóricometodológica entre a História Pública (HP) e História Oral (HO). $\mathrm{O}$ texto encontra-se estruturado em três partes. Na primeira, além de apresentarmos nossa perspectiva conceitual sobre HP, refletimos sobre a historicidade da noção de HP na Inglaterra, nos Estados Unidos e no Brasil, pontuando seus diversos cruzamentos com a HO. Em seguida, com base numa ampla pesquisa documental, perscrutamos os sentidos de História Oral e o papel atribuído ao historiador e ao conhecimento histórico durante a criação do Laboratório de História Oral da Universidade da Região de Joinville (LHO/Univille). Nesse fazer, analisamos como, no início dos anos 1980, esse espaço foi concebido como parte de uma rede de produção de fontes orais que envolvia numerosas instituições de ensino superior do sul do Brasil e, também, entidades internacionais de atuação multilateral, tais como a Organização dos Estados Americanos (OEA) e a Secretaria de Cooperação Técnica Internacional do Brasil, subordinada ao então Ministério de Educação e Cultura (SUBIN/MEC). No terceiro e último item, finalizamos o texto tecendo algumas considerações sobre os limites e as possibilidades reflexivas da HP quando articulada à $\mathrm{HO}$ e aos recentes debates sobre o papel público do historiador na escrita da História do Tempo Presente.
\end{abstract}

Palavras-chave: História Pública; História Oral; História do Tempo Presente; LHO/Univille.

\section{Para citar este artigo:}

COELHO, Ilanil; SOSSAI, Fernando Cesar. Aproximações entre história pública e história oral: o caso do Laboratório de História Oral da Univille. Revista Tempo e Argumento, Florianópolis, v. 8, n. 19, p. 96 - 129. set./dez. 2016.

\section{DOI: $10.5965 / 2175180308192016096$}

http://dx.doi.org/10.5965/2175180308192016096

\footnotetext{
${ }^{1}$ Este artigo resulta de uma pesquisa histórica realizada durante os anos de 2015 e 2016 em três acervos distintos, quais sejam: Arquivo Central da Universidade da Região de Joinville (Univille); Centro Memorial da Univille (CMU/Univille); Laboratório de História Oral da Univille (LHO/Univille: <http://houniville.wixsite.com/novo>).
} 


\section{Approximations between public history and oral history: the case of the Oral History Lab of Univille}

\begin{abstract}
This paper aims to build a theoreticalmethodological approximation between Public History $(\mathrm{PH})$ and Oral History $(\mathrm{OH})$. First of all, beyond presenting our conceptual perspective about HP, we carried out a reflection on the historicity notion of PH in England, United States and Brazil, pointing their several interactions with $\mathrm{OH}$. Later, supported by an extensive documental research, we have rigorously investigated the Oral History senses and the role attributed to the historian and to historical knowledge during the founding of Oral History Lab of University of the Joinville Region (LHO/Univille). We have analysed how, in the beginning of 1980's, it was idealized as part of a huge network, involving numerous universities from the South of Brazil, as well as international multilateral actuation institutions, like Organization of American States (OAS), and Secretaria de Cooperação Técnica Internacional do Brasil (Brazilian International Secretary of Technical Cooperation), at that time subordinated to Education and Culture Ministry (SUBIN/MEC). Finally, some considerations were done about reflective limits and possibilities of $\mathrm{PH}$ when articulated with Oral History as well as about latest discussions focusing the public role of the historians on History of the Present time.
\end{abstract}

Keywords: Public History; Oral History; History of the Present Time; LHO/Univille.

\section{Aproximaciones entre historia pública y historia oral: el caso del Laboratorio de Historia Oral de Univille}

\begin{abstract}
Resumen
En este artículo efectuamos una aproximación teóricometodológica entre la Historia Pública (HP) y la Historia Oral (HO). El texto está estructurado en tres apartados. En el primer, además de presentar nuestra perspectiva conceptual respecto a la $\mathrm{HP}$, reflexionamos sobre la historicidad de la noción de HP en Inglaterra, en los Estados Unidos y en Brasil, subrayando sus diversas intersecciones con la HO. A continuación, en base de una vasta investigación documental, examinamos los sentidos de la Historia Oral y del papel asignado al historiador y al conocimiento histórico a lo largo de la creación del Laboratorio de Historia Oral de la Universidad de la Región de Joinville (LHO/Univille). En ese quehacer, analizamos como en el comienzo de los 1980 el LHO/Univille ha sido concebido como parte de una red de producción de fuentes orales que involucraba numerosas instituciones de educación superior del sur de Brasil $y$, también, entidades internacionales de actuación multilateral, tales como la Organización de los Estados Americanos (OEA) y la Secretaria de Cooperación Técnica Internacional de Brasil, en ese momento subordinada al Ministerio de Educación y Cultura (SUBIN/MEC). En el tercer y último apartado, finalizamos el artículo con algunas consideraciones respecto los límites y las posibilidades reflexivas de la HP cuando se suma a la Historia Oral y a las recientes discusiones sobre el papel público del historiador en la escrita de la Historia del Tiempo Presente.
\end{abstract}

Palabras-clave Historia Pública; Historia Oral; Historia del Tiempo Presente; LHO/Univille. 


\section{Introdução}

Nos últimos anos, no Brasil, vem aumentando significativamente o número de historiadores/as que se dedicam tanto ao debate acadêmico quanto à promoção de atividades de ensino, pesquisa e extensão em História Pública (HP). A criação da Rede Brasileira de História Pública (<http://historiapublica.com.br>), em setembro de 2012, foi uma iniciativa importante no sentido de promover um espaço de interação entre “pesquisadores, profissionais, professores e estudantes interessados em refletir sobre a história pública", assim como para "estimular a prática de produção do conhecimento histórico dirigido a diferentes públicos, com um enfoque interdisciplinar" (REDE BRASILEIRA DE HISTÓRIA PÚBLICA , 2012).

Nesses domínios, a HP vem se mostrando como um ponto de efetivo encontro entre o que tem sido produzido por meio de projetos em História vinculados a universidades, arquivos, centros de memória, museus, memoriais, entre outros, e pessoas ou grupos sociais que até então teriam tido pouco ou nenhum acesso ao conhecimento cientificamente elaborado nestas mesmas instituições (Cf. NOIRET, 2015a, 2015b; DE ALMEIDA, 2016; EVANGELISTA, ROVAI, 2011; entre outros).

Considerando as complexidades que atravessam os recentes debates nesse âmbito, este artigo consiste num esforço de aproximação entre a HP e a metodologia da História Oral $(\mathrm{HO})^{2}$. Pontualmente, o texto foi estruturado em três seções. Na primeira, apoiados em expressivas publicações, refletimos sobre a historicidade da noção de HP na Inglaterra, nos Estados Unidos e no Brasil. No decorrer da discussão, além de apresentarmos nossa perspectiva conceitual de HP, também analisamos como a HP e a HO aproximaram-se com vistas à produção de conhecimento em História acerca do tempo presente e para além dos limites universitários.

\footnotetext{
2 De acordo com a Associação Brasileira de História Oral (ABHO, 2016), "a gravação de entrevistas com testemunhas da história teve início na década de 1950, após a invenção do gravador à fita, na Europa, nos EUA e no México. A partir dos anos 1970, as técnicas da história oral difundiram-se bastante e ampliou-se o intercâmbio entre os que a praticavam. Foram criados programas de história oral em diversos países e editados livros e revistas especializados na matéria". Nesse campo, desde 2011, por força dos nossos vínculos com o LHO/Univille, vimos procurando não apenas reunir e acompanhar a bibliografia produzida sobre a História Oral, como também promover reflexões e análises do estado da arte dessa metodologia por meio de escritos e de grupos de estudos sistemáticos. Parte desse esforço resultou nas seguintes publicações: Sossai e Mendes (2016); Coelho e Sossai (2015); Coelho, Sossai e Machado (2014); Sossai e Coelho (2011).
} 
Em continuidade, com base numa ampla documentação primária, empreendemos uma reflexão sobre a criação do Laboratório de História Oral da Universidade da Região de Joinville (Univille) ${ }^{3}$, pontuando como o espaço foi concebido, no início dos anos 1980, como parte de uma rede de produção de fontes orais que envolvia numerosas instituições de ensino superior do sul do Brasil e, também, organismos internacionais de atuação multilateral como a Organização dos Estados Americanos (OEA) e a Secretaria de Cooperação Técnica Internacional do Brasil, subordinada ao então Ministério de Educação e Cultura (SUBIN/MEC). Nesse fazer, apresentamos uma análise sobre as interações acadêmico-institucionais que levaram à constituição dos, à época, denominados Centros Regionais de História Oral, bem como problematizamos os sentidos de $\mathrm{HO}$ e o papel atribuído ao historiador e ao conhecimento histórico que perpassaram o projeto de implementação de tais Centros em diferentes cidades catarinenses.

Na terceira e última parte, concluímos o texto tecendo algumas considerações sobre os limites e as possibilidades reflexivas da HP quando articulada à $\mathrm{HO}$ e aos recentes debates sobre o papel público do historiador na escrita da História do Tempo Presente.

\section{História Pública e História Oral: cruzamentos e perspectivas}

Alguns historiadores têm construído aproximações interessantes entre História Pública e História Oral ${ }^{4}$. A partir de inventivas práticas de pesquisa, têm aflorado perspectivas e procedimentos analíticos bastante perspicazes, especialmente relacionados ao tratamento de fontes e à abordagem de fenômenos que até pouco tempo eram estranhos ao ofício de historiador. Nessa direção, não cremos ser exagerado

\footnotetext{
${ }^{3}$ A Univille tem como mantenedora a Fundação Educacional da Região de Joinville (FURJ). Trata-se de uma Fundação criada pelo poder municipal de Joinville, na década de 1960, com o intuito de implantar o ensino superior na região norte e nordeste de Santa Catarina. A iniciativa emergiu das articulações, em âmbito estadual, entre empresários e políticos de várias cidades catarinenses que viam a interiorização do ensino superior como uma estratégia econômico-desenvolvimentista para suas regiões. Antecederam à FURJ outras Fundações criadas pelos poderes públicos municipais de Blumenau (Lei Municipal 1233/64), de Itajaí (Lei Municipal 599/64) e de Tubarão (Lei Municipal 35364). A esse respeito ver: Coelho e Sossai (2015).

${ }^{4}$ Um mapeamento de escritos que promovem tal aproximação pode ser encontrado no trabalho de Santhiago (2011). Além desse, também são importantes nessa direção os estudos de: Mauad, De Almeida e Santiago (2016); De Almeida (2016); Santhiago (2016); Uribe e Coelho (2016).
} 
dizer que a HP vem empreendendo um esforço historiográfico relevante no sentido de interpretar práticas sociais que são próprias do contemporâneo (tais como os acontecimentos digitalmente suportados nas redes sociais). Também é digno de nota que a HP tem oportunizado diálogos com públicos que não eram diretamente alvos dos produtos que tradicionalmente resultavam do trabalho historiador, isto é, teses, livros, artigos, relatórios de pesquisas acadêmicas etc (SANTHIAGO, 2016).

Cientes do potencial reflexivo oportunizado pela História Pública, ao longo desta seção, além de apresentarmos uma discussão sobre a historicidade da noção de HP nos Estados Unidos, na Inglaterra e no Brasil, dialogamos com um conjunto de trabalhos em que a HP e a HO foram combinadas durante o processo de produção de conhecimentos em História. Dentre outros objetivos, buscamos explicitar o embasamento teórico que sustenta as reflexões presentes neste texto.

Para começar, vejamos alguns aspectos relativos à emergência da HP na produção historiográfica. De acordo com Fien Danniau (2013, p. 119), “o termo Public History Movement apareceu nos Estados Unidos nos anos 1970 como um movimento prático de historiadores que desejavam trabalhar fora das instituições de pesquisa e utilizavam métodos históricos para objetivos não acadêmicos" $" 5$.

Um marco significativo na trajetória dos estudos em HP foi a criação, em 1979, do National Council on Public History $(\mathrm{NCPH})^{6}$, junto à Universidade da Califórnia. À época, o "número de vagas de professor nas universidades americanas tornou-se mais limitado", fazendo com que "um maior número de historiadores buscassem empregos em sociedades históricas, museus, órgãos governamentais, empresas privadas e outros espaços fora da academia tradicional”. Longe de figurar como mais uma entre as numerosas associações de História dos Estados Unidos, a constituição do NCPH respondia a dois tipos de interesses. De um lado, o dos "praticantes da História Pública [...] que desejavam uma organização profissional que supriria suas preocupações e interesses". E, de outro, "simbolizava as mudanças na profissão histórica" diante de

\footnotetext{
${ }^{5}$ Neste artigo, todos os excertos traduzidos do inglês ou do espanhol são Traduções Livres. À exceção de substantivos próprios, transpomos ao português a totalidade da frase, sempre respeitando seu contexto de discussão.

${ }^{6}$ Informações detalhadas sobre o NCPH podem ser encontradas no seguinte endereço: <http://ncph.org >.
} 
Ainda que a fundação do NCPH tenha sido uma iniciativa de grande monta, contribuindo significativamente para maior visibilidade dos debates em HP, é bom termos a cautela de não lhe atribuirmos um equivocado ineditismo. Não podemos esquecer que desde 1978 - portanto, um ano antes da fundação do NCPH - circulava na mesma Universidade da Califórnia o periódico Public Historian, tendo como Editor o historiador G. Wesley Johnson (que posteriormente se tornaria o primeiro presidente do NCPH) ${ }^{7}$. Além disso, já eram bem conhecidos os cursos de graduação e pós-graduação em HP oferecidos pelo Departamento de História dessa mesma Universidade (JOHNSON, 2015).

Se recuarmos no tempo, é preciso considerar que, na Europa, os estudos em HP são ainda mais antigos. Conta-nos Danniau que "embora possuísse um nome diferente", a História Pública europeia remonta ao final dos anos 1960, quando, no âmbito do British History Workshop Movement, Raphael Samuel "defendia uma história vista de baixo e uma história radical”, lançando mão da "escrita histórica para discutir problemas sociais". Segundo a autora, por intermédio de "oficinas públicas, Samuel promovia a historiografia como um empreendimento intelectual colaborativo", no qual o "pesquisador, o arquivista, o curador, o professor, o entusiasta do 'faça-você mesmo', o historiador local, as sociedades de história familiar e o arqueólogo individual, poderiam todos ser considerados como igualmente comprometidos" (DANNIAU, 2013, p. 119).

Também sobre a emergência da HP no Reino Unido, De Almeida e Rovai (2013) oferecem-nos alguns detalhes. De acordo com as autoras, depois de um conjunto de “oficinas realizadas desde 1967 em Oxford", em 1976, foi organizada a revista "History Workshop Journal", por Raphael Samuel ${ }^{8}$. No transcurso das oficinas, bem como nas

\footnotetext{
7 Conforme Jill Liddington (2011, p. 35), o Jornal reunia um "corpo editorial que incluía não somente a universidade de elite [Universidade da Califórnia] e o Oral History Institute, bibliotecas e museus, mas também o US Department of State Office of the Historian, o Wells Fargo Bank e o US Army Center of Military History". Quer dizer, membros vinculados ao "Governo, capitalismo, exército". Também por isso o Periódico "foi alvo de ataque" de outros historiadores, que questionavam a sua "perspectiva corporativa".

${ }^{8}$ Há informações sobre a Revista em: <http://www.historyworkshop.org.uk>. Acesso em: 10 set. 2016.
} 
páginas da Revista, Samuel defendia que a "história deveria extrapolar os espaços acadêmicos, como conhecimento público" que era. Notadamente influenciado pela repercussão da obra The Making of the English Working Class (THOMPSON, 1963), Samuel acreditava que cumpria aos praticantes da História "democratizar e refletir sobre os usos políticos do passado no presente" (DE ALMEIDA; ROVAI, 2013, p. 2).

Aliás, a bem da verdade é que a perspectiva de História defendida por Samuel anunciava a HP em meio a debates mais amplos acerca dos usos do passado e da História inglesa. Ao longo das décadas de 1960, 1970 e 1980, havia diversos historiadores que criticavam as utilizações mercadológicas "do patrimônio e da memória nacional" da Inglaterra. Jill Liddington (2011, p. 40) assim explicou as contribuições de Samuel nesse debate:

\begin{abstract}
Salvando o "patrimônio das pessoas" destes "destruidores de patrimônio", Raphael Samuel surgiu como um [...] defensor. Seu afetuosamente eclético Theatres of memory (1994) celebrava o "conhecimento não oficial" e a memória popular, contra Wright, o "reacionário chic", e Hewison, o "aristocrata conspirador". Samuel traçou as raízes de "patrimônio" até os desfiles da "Marcha pela História" dos socialistas dos anos 1930 e os parques nacionais do governo Attlee [...]. Patrimônio, ele afirmou, teria menos a ver com casas de campo e mais com humildes casebres provincianos, com a preservação das antigas técnicas artesanais (como as associações de ferrovias a vapor) e atividades plebeias (como os vendedores de barraquinhas "retrô-chic"). Ele atacou a condescendência dos heritagesbaiters ${ }^{9}$, chamando-os de esnobes literários misóginos, e procurava, ainda que brevemente, nos Estados Unidos e na Austrália inspiração para a história pública [...]" (Liddington, 2011, p. 40, grifos no original)
\end{abstract}

Embora o trabalho de Samuel seja considerável, de fato, para Liddington, "o que emergiu na Grã-Bretanha foi o English Heritage (um quango ${ }^{10}$ com fundos governamentais criado em 1983)". Foi somente em meados da década de 1990 que a HP ganhou mais

\footnotetext{
${ }^{9}$ No inglês britânico, a expressão "heritage-baiters" possui uma interessante dubiedade de significados. Por um lado, o termo se refere a pessoas fabricadoras ou inventoras de patrimônios. De outro, também diz respeito a indivíduos que fazem as vezes de porta-vozes de patrimônios, nomeadamente indivíduos que tentam moderar os enunciados históricos que certos bens culturais poderiam comunicar à sociedade.

${ }^{10} \mathrm{Na}$ Grã-Bretanha, QUANGO (ou QANGO) é uma expressão empregada como abreviação de quasi nonGovernmental Organisation. Grosso modo, a sigla transporta para o vocabulário cotidiano alguns termos do Sistema Administrativo Britânico, combinando-os entre si: "G (Government)", "NG (nonGovernment)", "QG (quasi-Government)" e "QNG (quasi-non-Government)" (JORDAN, 2005, p. 25).
} 
“usos e representações públicas de história oral em uma grande variedade de mídias", (LIDDINGTON, 2011, p. 40-41). Desde então, a HP ascendeu vertiginosamente, inclusive ganhando espaço na pós-graduação, como, por exemplo, o curso de MA in Public History (Mestrado em História Pública), oferecido desde 1996 pelo Ruskin College, em Oxford ${ }^{11}$.

Do nosso ponto de vista, o aparecimento da HP em países como os Estados Unidos e a Inglaterra foi movido por múltiplos cruzamentos com a HO num contexto de renovação da produção historiográfica. No caso dos EUA, o desenvolvimento do NCPH foi fortalecido por relações institucionais mantidas com uma rede de associações históricas já consolidas. Além de ter contato com o apoio do Oral History Institute, o NCPH, no começo de 1980, "realizou reuniões conjuntas com a Society for History in the Federal Government, o Southwest Oral History Association, e outras organizações”. Conforme o seu próprio site, essas "reuniões desempenharam um papel importante na criação do NCPH", sobretudo para a ampliação do debate acerca de "aspectos teóricos e práticos da história pública" (INDIANAUNIVERSITY, 2016).

Além disso, cumpre lembrar que a tradicional Oral History Review - um periódico estadunidense criado em 1966 pela Oral History Association (OHA) - no volume 8, de 1980, apresentou como primeiro artigo o texto intitulado "Oral History and Public History", de autoria de Enid H. Douglass (então presidenta da OHA - gestão 1979-1980), recuperando momentos importantes da relação desta Associação com o começo dos estudos em HP nos Estados Unidos. Conta-nos Douglass (1980) que, em 1979, ela teria participado do “primeiro Simpósio Nacional sobre História Pública em Santa Barbara, Califórnia”. Tal Simpósio foi “organizado pelo Programa de Graduação em Estudos Históricos Públicos da Universidade da Califórnia de Santa Barbara", com o apoio da Fundação Rockefeller. Procurando discutir os "próximos passos na formação de algum tipo de rede ou organização para pessoas interessadas em História Pública”, o Simpósio teve a Há uma descrição sobre a atual proposta pedagógica desse Curso em:
<https://www.ruskin.ac.uk/perch/resources/mapublichistoryfactsheet.pdf>. Acesso em: 10 set. 2016. 
participação de vários historiadores, entre eles Charles Morrissey, um "antigo Presidente da Oral History Association" (gestão 1971-1972) (DOUGLASS, 1980, p. 1-2).

No que tange à Inglaterra, também há uma clara sintonia entre a metodologia da HO e o embrionário trabalho de HP empreendido por Raphael Samuel. A esse respeito, conta-nos Stuart Hall que, em 1957, “dois ex-comunistas (Raphael e Gabriel Pearson) e dois socialistas independentes (eu e 'Chuck' Taylor)” passaram a editar o periódico Universities and Left Review ("que em 1960 fundiu-se com o The New Reasoner para formar a New Left Review"). Tal Publicação teria sido concebida levando em consideração as sugestões de Raphael e, mais precisamente, o seu "olhar aguçado para os meandros da genealogia política” da Grã-Bretanha. Em seu primeiro número, lançado em 1957, o Universities and Left Review divulgou textos de alguns proeminentes intelectuais, quais sejam: Isaac Deutscher, Claude Bourdet, Lindsay Anderson, E. P. Thompson, G. D. H. Cole, Eric Hobsbawm, Joan Robinson e Basil Davidson (HALL, 1997, p. 121). Especificamente em relação à História Oral, lembra-nos Hall que, a partir de 1961:

Raphael trabalhou por um tempo entrevistando pessoas na East London [zona leste da Cidade] para a equipe do Institute for Community Studies, Peter Willmott e Michael Young - uma experiência que impulsionou o seu compromisso com o lugar das técnicas orais na história social, técnicas que ele fez um uso espetacular na entrevista com o criminoso da East End, Arthur Harding, publicada em East End Underworld (1981) - e se mudou para o número 19 da Rua Elder, em Spitalfields, que se transformou numa casa aberta e num centro hospitaleiro para uma variedade extraordinária de pessoas que compartilhavam sua crescente obsessão apaixonada com todos os detalhes da história da vida diária e de trabalho popular de Londres. (HALL, 1997, p. 123)

Também à época, uma das principais intenções de Samuel não era "ensinar" aos outros a "história social". Mais importante do que isso, era "fazer dos outros os historiadores sociais de suas próprias vidas e culturas e os ativos custodiantes de suas próprias memórias populares". Em seu trabalho, ele buscava estimular as pessoas a "falarem a partir de seus conhecimentos", isto é, a "falarem para o mundo a partir do que sabiam", demonstrando um profundo respeito pela "riqueza da experiência vivida" (HALL, 1997, p. 123-124). 
Ademais, é importante mencionar mais um dado sobre as articulações entre a HO e a emergência da HP na Inglaterra: a primeira edição da revista History Workshop (1976), trouxe "sob a própria autoria de Raphael Samuel [...] um artigo sobre história local e história oral no qual ele afirmava: 'a partir do uso de diferentes classes de registros, o historiador pode preparar novos mapas, nos quais tanto pessoas como lugares estão realçados, e os dois estão mais intimamente entrelaçados"” (KEAN, 2004, p. 54) ${ }^{12}$.

Ao que tudo indica, parecia haver uma ligação orgânica entre a metodologia da História Oral e os preliminares estudos ingleses sobre História Pública.

Em se tratando do Brasil, a aproximação entre HP e HO tem ganhado cada vez mais espaço em recentes estudos historiográficos. Entre outros, vale a pena mencionar que são relevantes os trabalhos de Mauad, De Almeida e Santhiago (2016); De Almeida (2016); Santhiago (2016; 2011); Lucchesi (2014); De Almeida e Rovai (2013; 2011); Vianna (2013); Fonseca (2012); Evangelista, Rovai e Ribeiro (2011); Chalhoub e Fontes (2009). Tais trabalhos assumem o desafio de refletir teórica e metodologicamente acerca da HP e valorizar suas zonas de contato com uma metodologia já bastante difundida entre os historiadores brasileiros, a HO.

Nesses escritos, em meio à abordagem de diferentes questões de pesquisa, os/as autores/as manifestam interesses em relação aos contemporâneos desafios que interpelam a prática da HP quando aproximada à HO, destacadamente: i) a reflexão histórica frente à acentuada expansão de fontes digitais; ii) os diversificados usos do passado e da memória nos meios de comunicação (mercadológicos, políticos, pedagógicos etc.); iii) a potência da HP e da HO nos processos de ensino e aprendizagem em História; iv) a profusão de repositórios online que coletam e difundem narrativas de memória em diversos suportes; v) a cogente reconfiguração do ofício de historiador para que, no exercício de sua profissão, demonstre ainda mais comprometimento com as demandas advindas da sociedade no tempo presente (compartilhamento e acesso

\footnotetext{
${ }^{12}$ Refere-se a historiadora Hilda Kean ao artigo "Local History and Oral History", originalmente publicado em Samuel (1976), no qual o autor reflete a respeito da "pesquisa sobre história de família" e suas possíveis articulações com a História Oral (KEAN, 2004, p. 54).
} 
democrático ao conhecimento histórico cientificamente produzido pelo historiador acadêmico); vi) as relações entre HP,HO e movimentos sociais.

Ainda a respeito dos cruzamentos entre HP e $\mathrm{HO}$ em nosso país, De Almeida e Rovai (2013, p. 5) defendem que o trabalho de Meihy (1991), "aliando história oral, história pública e política pública no Brasil, desenvolvido com a nação kaiowá”, poderia ser considerado um "trabalho pioneiro", já que em suas "práticas de história oral”, Meihy teria produzido e socializado "conhecimento histórico" com, sobre e para "setores da sociedade entendidos como à margem do próprio processo histórico”. Entretanto, ainda carecemos de investigações com maior densidade documental e amplitude historiográfica para sustentar esse suposto pioneirismo.

A propósito, convém ressalvar que no seu livro, Meihy não utilizou a expressão História Pública. Ele empregou os termos "público" ou "pública” para sublinhar o potencial científico-social da História Oral, bem como de outros procedimentos científicos que poderiam contribuir para o amplo compartilhamento do conhecimento histórico produzido por pesquisadores universitários. A seguir, transcrevemos um excerto que ilustra adequadamente o esforço intelectual do referido autor:

Porque no Brasil segmentos da população tem sido contemplados apenas pela documentação externa, produzidas "sobre" eles, qualquer nova proposta que se oriente em cortar o caminho disposto pelo "outro", se mostra digna de consideração. Métodos e procedimentos de trabalho, contudo, merecem discussão, a fim de se esclarecer trajetos e explicar atitudes. Nessa conduta, aliás, reside o caráter público do procedimento da história oral.

Antes de mais nada é importante que se considere o significado da inscrição deste trabalho nas linhas da proposta acadêmica. Fala-se, porém, de um novo discurso universitário empenhado no envolvimento de maiores contingentes de leitores. Concomitantemente deve ser salientado que a proposta de um estudo de apelo amplo, não apenas voltado ao público especial, se diferencia do mero trabalho constatativo. Pelo contrário, o que se propõe é um texto acessível, aberto, de leitura agradável, mas que exponha de forma penetrante o problema da colônia indígena de Dourados. No caso, a questão mestra inspiradora deste trabalho foi o suicídio dos índios sul-mato-grossenses e com isso se afirma que este esforço universitário é público porque se remete a uma proposta socialmente comprometida e ao mesmo tempo "científica". Pretende-se um texto acessível, aberto, mas também a ser cifrado pelo reconhecimento dos pares. (MEIHY, 1991, p. 15-16; grifos nossos) 
De nossa perspectiva, mais profícuo do que empreendermos buscas no sentido de elucidar as origens da relação entre História Pública e História Oral no Brasil, seria necessário identificar estratégias historiográficas autoconscientes em HP. Em outras palavras, ainda nos faltam estudos sobre como, num determinado momento, historiadores e historiadoras declaradamente assumiram os aportes teóricometodológicos da HP. Desta forma, poderemos avançar na compreensão das complexidades epistemológicas envolvidas com a produção de estudos em HP (sejam ou não cruzados com a metodologia da História Oral).

Do mesmo modo, investigar como ocorreram as composições acadêmicoinstitucionais que levaram à fixação de marcos mais sólidos relacionados com o advento da HP no país, poderia ser um primeiro passo para compreendermos como a História Pública acionou a metodologia da História Oral para se expressar e, também, para garantir certa legitimidade entre os que atuam no campo da História no Brasil. Nessa direção, é emblemática a fundação da Rede Brasileira de História Pública, em 25 de setembro de 2012. Em sua "Carta de Fundação", não encontramos qualquer menção à expressão "História Oral" e/ou a termos frequentemente a ela relacionados (oralidade, memória e narrativas orais...). Todavia, se levarmos em consideração que, no segundo parágrafo da referida Carta, informa-se que no próprio ano de "2012", no "âmbito do Departamento de História", da "Universidade de São Paulo", foi realizado o "Simpósio Internacional de História Pública", algumas aproximações entre a HP e a HO podem ser vislumbradas (REDE BRASILEIRA DE HISTÓRIA PÚBLICA, 2012). Ao apreciarmos a nominata dos integrantes das Comissões Organizadora e Científica desse Simpósio, encontramos vários pesquisadores que vêm lidando sistematicamente com o ensino, a pesquisa e/ou a extensão universitária em História Oral, muitos dos quais possuindo elevado número de publicações sobre diversos temas em HO. Alguns deles, inclusive, em algum momento de suas vidas, foram presidentes ou diretores da Associação Brasileira de História Oral (ABHO) (REDE BRASILEIRA DE HISTÓRIA PÚBLICA, 2012). E, verdade seja dita, a edição subsequente do mesmo Evento, ou seja, o " 2 Simpósio Internacional de História Pública", realizado em 2014, na Universidade Federal Fluminense (UFF), além de uma "Sessão oficial de abertura" que contou com a presença de representantes “[...] do 
Laboratório de História Oral e Imagem" da UFF e da "Associação Brasileira de História Oral", foi marcado pela "Conferência de abertura" intitulada "História oral e história pública”, proferida por “Linda Shopes” (REDE BRASILEIRA DE HISTÓRIA PÚBLICA, 2014).

Chegados a este ponto, não restam dúvidas de que é equivocada a afirmação de Davison (1991, p. 4) de que a "História Pública é o novo nome para a mais antiga história de todas". Embora a frase tenha sido pronunciada há mais de 15 anos, num tempo em que a HP era pouco conhecida, vez ou outra, ela é externada com ares de ironia por nossos colegas de profissão que questionam sua potência para atribuir uma nova condição ao conhecimento da história no tempo presente. Aceitando a divergência como uma saudável característica do campo da História, cremos que o que foi explicitado até aqui é suficiente para demonstrar como a HP foi sendo construída como uma perspectiva científica, e socialmente comprometida, de trabalho intelectual em História.

Acompanhando o posicionamento de Noiret, acreditamos que a "história pública é uma disciplina global que considera a presença do passado - e a construção da história para além de suas configuraçõos acadêmicas”. Como uma ramificação do conhecimento histórico, a HP interessa-se por discutir "percepções conflitivas do passado", problematizando suas “diferentes abordagens históricas", bem como a "incapacidade de esquecer" que o nosso tempo tem demonstrado (NOIRET, 2014, p. 1-2). Nesse sentido, ela não deve ser entendida como sinônimo de todos os usos públicos do passado, tampouco como equivalente a qualquer prática pública da História. A HP é, pontualmente, um lugar intelectual (não o único) de onde podemos partir para "interpretar criticamente" tais usos/práticas, valorizando o "papel do historiador" na mediação das "formas públicas do conhecimento histórico" (NOIRET, 2015b, p. 66).

Conforme procuramos demonstrar, os movimentos em prol da História Oral e da História Pública produziram afinidades emergentes das interpelações sobre como, porque e para quem se volta o conhecimento histórico, já que ambas tem "atraído praticantes e públicos diferentes daqueles da escrita histórica mais tradicional" (RITCHIE, 2003, p. 41). Mais do que tratá-las como meros receptáculos ou meios de conhecimento histórico, a prática da HP e da HO exige do historiador considerar seus públicos como ativos produtores de significados sobre o passado e como habilidosos comentaristas da 
história do presente. Por meio delas, o que se coloca em evidência são os desejos de saber que se evadem do habitual universo acadêmico-universitário, exigindo do historiador uma autopercepção crítica sobre o lugar que ocupa na escrita histórica do e para o tempo presente.

Em sintonia com o que apresentamos até aqui, vejamos um caso concreto no qual a figura do historiador foi essencial para a gestão de espaços públicos relativos à produção, organização e difusão de fontes orais seguindo critérios específicos da metodologia da História Oral. Referimo-nos, pois, ao intrigante caso do Laboratório de História Oral da Univille.

\section{A constituição do Laboratório de História Oral da Univille: redes acadêmicas e compartilhamento de fontes de pesquisa histórica}

De maneira geral, o LHO/Univille pode ser caracterizado como um espaço dedicado à promoção de ações de ensino, pesquisa e extensão em História Oral, atuando nas regiões norte e nordeste de Santa Catarina.

Articulado ao Departamento de História, ao Mestrado em Patrimônio Cultural e Sociedade e à Pró-reitoria de Extensão e Assuntos Comunitários da Univille, o LHO/Univille tem buscado se constituir como um ambiente de experimentação e de interação entre interessados que utilizam a metodologia da História Oral para fins acadêmicos ou não, bem como se posicionar como vetor de integração de projetos que, de alguma maneira, acionam a $\mathrm{HO}$ em seus fazeres.

Vinculado ao Programa Institucional de História Oral da Univille, o LHO/Univille também tem procurado contribuir para o fortalecimento e a expansão de práticas em HO por meio do oferecimento gratuito às comunidades interna e externa da Universidade de: equipamentos digitais para gravação de entrevistas (gravadores, câmeras fotográficas, filmadoras, computadores); salas individuais e coletivas para realização de entrevistas; assessoria especializada para o processamento técnico de entrevistas (elaboração de roteiro, termo de doação, sumário da entrevista, fichas técnicas, orientações quanto à transcrição, produção de cópias de segurança do áudio gravado etc.); e banco de dados 

(temporárias), valendo-se das coleções integrantes de seu acervo.

Em relação ao acervo, nos últimos 35 anos, foi sendo composto por doações de entrevistas resultantes de projetos com temáticas bastante variadas (educação, economia, meio ambiente, migração, patrimônio cultural, política, saúde, memórias institucionais, entre outras). Atualmente, possui 43 coleções, que perfazem o total de 653 entrevistas. Todas estão disponíveis para consulta pública, sem qualquer custo (LHO, 2016).

Além de possuir uma equipe técnica permanente, integrada por dois historiadores, um estagiário e dois alunos-bolsistas de graduação em História, o Laboratório conta com uma Comissão de Acervo formada por nove membros, entre os quais historiadores, educadores, arqueólogo e estudantes de cursos de graduação e pós-graduação da Univille. Esta Comissão reúne-se periodicamente para deliberar sobre "descarte e eliminação de documentos do acervo, incorporação de novas entrevistas orais ao acervo, propor reformulações nos objetivos e nas estratégias de ação do LHO/Univille" (SOSSAI e COELHO, 2014, p. 7).

No que diz respeito à sua trajetória institucional, a criação ocorreu em 1982. Porém, a primeira entrevista incorporada ao acervo foi realizada em 1978. Trata-se de uma entrevista da professora Dúnia Anjos de Freitas com o político Pedro Ivo Campos ${ }^{13}$. Esse descompasso cronológico e o perfil do próprio entrevistado foram tomados por nós como os primeiros indícios no levantamento de uma vasta documentação sobre a iniciação de pesquisadores brasileiros na História Oral e os movimentos em prol da implantação de uma rede de instituições catarinenses voltadas à disseminação da metodologia e à divulgação pública de acervos orais.

Em uma publicação alusiva a uma entrevista que realizou com o historiador Carlos Humberto Pederneiras Corrêa pouco antes de sua morte, Ricardo Santhiago (2015, p. 223)

\footnotetext{
13 Pedro Ivo Campos (1930-1960) foi prefeito de Joinville de 1973 a 1977, governador de Santa Catarina de 1987 a 1990 e deputado federal por dois mandatos (1971-1975 e 1979-1983) (Cf. COELHO e SOSSAI, 2015).
} 
disciplina de Metodologia da Pesquisa, ministrada pelo professor Dr. George P. Browne, da Seton Hall University, de New Jersey. No ano seguinte, o Curso foi convertido em mestrado, dando-se início ao Programa de Pós-Graduação em História da UFSC (PPGH/UFSC).

Conforme o primeiro coordenador desse Programa, Walter F. Piazza, naquele período desejava-se impulsionar a pesquisa histórica catarinense, para além do que era produzido pelo Instituto Histórico e Geográfico de Santa Catarina. Para tanto, além da criação do PPGH/UFSC, e articulado a ele, houve a formalização do projeto "Perfil socialeconômico de Santa Catarina com base em fontes primárias", que, também sob sua coordenação, previa a implantação dos programas de pesquisa em História Oral, História Demográfica e Indexação de Documentação Histórica (PIAZZA, 1982, p. 103).

Um dos primeiros alunos do Mestrado em História da UFSC foi Carlos Humberto Pederneiras Corrêa que, em 1975, participou de um curso também ministrado pelo professor George P. Browne, promovido pela Fundação Getúlio Vargas em parceria com a Universidade Federal Fluminense. Foi nesse mesmo ano que o Programa de História Oral da UFSC teve início e, segundo Piazza (1982, p. 104), as atividades envolveram planejamento, gravação, transcrição e indexação de entrevistas “da maior relevância para o estudo da história recente do país e da região”.

Em 1977, foi editado por Corrêa o Catálogo de História Oral da UFSC, reunindo informações sobre um acervo com 34 entrevistas realizadas com pessoas de várias regiões de Santa Catarina acerca de temas e episódios relacionados, entre outros, à colonização estrangeira do estado e aos arranjos políticos regionais e municipais. Contudo, observou Schütz, de 1977 a 1985, dos 43 alunos e alunas que defenderam suas dissertações, "apenas duas alunas não contam com entrevistas de sua autoria armazenadas no Laboratório" (SCHÜTZ, 2015, p. 74). Dentre elas, Eneida Raquel de S. 
Thiago, professora que desenvolveu com Dúnia Anjos de Freitas, em 1982, a implantação do Laboratório de História Oral na então FURJ ${ }^{14}$.

Do nosso ponto de vista, essa ausência pode ser explicada não por falta da adesão dessas historiadoras ao Programa de História Oral da UFSC, sob coordenação de Corrêa. Ao contrário, com base nas Atas de Reuniões do Departamento de Ciências Sociais da Faculdade de Filosofia, Ciências e Letras de Joinville (FFCLJ) é possível vislumbrar o envolvimento dessas professoras num trabalho pelo qual se pretendia criar e fortalecer uma rede entre pesquisadores e instituições envolvidos com a História Oral. Dois aspectos podem ser considerados como principais vetores dessa articulação.

Em primeiro lugar, é preciso destacar que os próprios professores Piazza e Corrêa eram docentes atuantes na criação (1968) e no funcionamento dos primeiros anos do Curso de História da FFCLJ. Piazza foi, inclusive, o primeiro a exercer a "presidência do Departamento de Ciências Sociais". Conforme se constata pelas Atas, eram esses professores que indicavam docentes recém formados a assumirem cadeiras como assistentes no Curso. Não é de se estranhar, por isso, a aproximação entre alguns docentes e atividades de pesquisa histórica da UFSC e da FURJ até pelo menos meados da década de 1980. Para se ter uma ideia, ainda em 1971, Piazza criou o Centro de Estudos Históricos de Joinville, congregando alunos "para efetivação de trabalhos de História Regional" (Ata N. 05, de 29 de março de 1971, p. 4). Entre os alunos matriculados nas primeiras turmas que, posteriormente, envolveram-se com a pesquisa histórica e alguns com a História Oral em âmbito estadual, destacam-se: Rufino Porfírio de Almeida e Edmundo Vegini, ingressantes na primeira turma daquele Curso de História, Afonso Imhof (1969), Eneida Raquel S. Thiago (1970) e Dúnia Anjos de Freitas (1971).

Em segundo lugar, em Santa Catarina, a configuração da própria rede de instituições de História Oral foi possibilitada pelas articulações políticas entre dirigentes da UFSC, das instituições de ensino superior integrantes da Associação Catarinense de

\footnotetext{
${ }^{14}$ De acordo com Coelho (2015, p. 27), a Univille "tem como marco inicial a criação da Faculdade de Ciências Econômicas em 1965 pela Comunidade Evangélica de Joinville, faculdade essa que foi incorporada à Fundação Joinvilense de Ensino (FUNDAJE), instituída pelo poder público municipal em 1967. Em 1971 a denominação Fundaje foi alterada para Fundação Universitária do Norte Catarinense (FUNC), a qual em 1975 passou a ser denominada Fundação Educacional da Região de Joinville (FURJ), atual mantenedora da Univille".
} 
vislumbrar como isso teria ocorrido.

Em 18 de junho de 1980, Piazza encaminhou para Silvio Coelho dos Santos, à época professor do Departamento de História e Pró-reitor de Pesquisa e Pós-Graduação da UFSC, um Ofício (UFSC, Of. 157, 1980) informando que a OEA, por intermédio de seu escritório em Brasília, havia aprovado o "Plano de Operações para a execução do Projeto Piloto de Centros Regionais de História Oral" (Projeto S68146/Brasil). Anexo havia o aludido Plano e outro documento assinado pelo Secretário-Geral Interino do MEC, o catarinense Pedro Demo ${ }^{16}$, informando que a Secretaria de Cooperação Internacional (SUBIN/MEC) também destinaria verba, a ser implementada no decorrer de 1980, para implantação dos Centros Regionais de História Oral nas cidades de Blumenau, Caçador, Chapecó, Joinville, Lages, Tubarão e Mafra (BRASIL, Of. MEC/SEG/SEAI/CODAM, 1980).

Segundo o Plano enviado, a verba captada junto à OEA estava destinada à promoção de um curso de "capacitação de pessoal para dirigir a condução e o processamento de entrevistas", bem como para "coordenar o arquivamento e a utilização do material colhido de acordo com os critérios internacionais aceitos" (MEC, 1980 , p. 2). O curso seria realizado na UFSC durante quinze dias e os participantes deveriam obrigatoriamente ser formados em História ou Ciências Sociais e possuírem vínculo empregatício com as instituições de ensino superior a serem integradas, por meio de convênio, ao Projeto. Como "contrapartida nacional”, a SUBIN/MEC destinaria

\footnotetext{
${ }^{15}$ A ACAFE é uma entidade sem fins lucrativos criada em 1974 "pelos presidentes das fundações educacionais municipais e estadual com a missão de promover a integração dos esforços de consolidação das instituições de ensino superior por elas mantidas, de executar atividades de suporte técnico-operacional e de representá-las junto aos órgãos dos Governos Estadual e Federal" (ACAFE, 2014).

${ }^{16}$ Graduado em Filosofia, Demo doutorou-se em Sociologia, em 1971, pela Universität Des Saarlandes, Alemanha. É Professor Titular Aposentado da Universidade de Brasília. Em sua experiência profissional, destaca-se o período que foi Secretário-Geral Adjunto do MEC, de 1979 a 1983, e Diretor Geral do Instituto Nacional de Estudos e Pesquisas Educacionais (INEP), de 1984 a 1985. Informações disponíveis em: <http://lattes.cnpq.br/1988962364420428>. Acesso em: 20 set. 2016.
} 
Conforme dito anteriormente, os Centros Regionais de História Oral foram concretizados também graças à adesão de instituições de ensino vinculadas à ACAFE. Assim sendo, Lauro Ribas Zimmer, reitor da Universidade do Estado de Santa Catarina (UDESC) e então presidente da ACAFE, em julho de 1980, comunicou à direção da FURJ que a entidade apoiaria a implantação dos referidos Centros, destinando recursos para aquisição de equipamentos necessários à constituição de Laboratórios de História Oral em cada instituição. Ademais, solicitou uma manifestação formal da FURJ quanto à aceitação do Projeto e à indicação de candidato ao curso patrocinado pela OEA e que, num futuro próximo, assumiria a direção local do Centro Regional de História Oral. A contrapartida institucional para a adesão ao Projeto consistia em "oferecer condições de trabalho ao [futuro] Diretor do Centro, tais como espaço físico exclusivo, datilógrafo e transcritor de textos" (ASSOCIAÇÃO CATARINENSE DAS FUNDAÇÕES EDUCACIONAIS, Of. 1448,1980$)$.

Poucos dias após o recebimento do Ofício de Zimmer, o Departamento de Ciências Sociais da FFCLJ indicou Dúnia Anjos de Freitas para realizar o mencionado Curso. Segundo informações fornecidas pela própria professora Dúnia, ela já tinha participado de uma capacitação sobre História Oral ministrada por Carlos Humberto P. Corrêa em Joinville e realizado, em 1978, a entrevista com o ex-prefeito Pedro Ivo Campos. Ainda que essa entrevista conste do acervo do LHO/Univille, as fitas contendo seis horas de gravação foram doadas ao Laboratório de História Oral da UFSC, como se lê na própria transcrição do áudio gravado:

Dúnia Anjos de Freitas: em primeiro lugar, gostaríamos de pedir que o senhor fizesse um "Termo de Doação" desta nossa entrevista, dizendo que o senhor faz doação das declarações que aqui fizer, para o Laboratório de História Oral da Universidade Federal de Santa Catarina

\footnotetext{
17 A verba da OEA correspondia a USD 8.900,00 para cobertura de viagens e estadias dos quinze participantes e para contratação, por seis meses, de serviços de datilografia e de transcrição. A contrapartida nacional era equivalente a 20\% do total captado junto à OEA (USD 1.246,00) (MEC, 1980, p. 5).
} 
de forma que, num futuro próximo, possa ser pesquisado por qualquer aluno que dele fizer uso e que vai servir de fonte histórica.

Pedro Ivo Campos: devo inicialmente cumprimentar a UFSC e particularmente o Curso de Pós-Graduação de História, que em convênio com a FURJ, realizam em nossa cidade de Joinville, o primeiro curso de Pós-Graduação ${ }^{18}$. Além da satisfação de poder prestar o meu depoimento a respeito das atividades das quais participei, tomei conhecimento e vivi. É sem dúvida alguma, razão para uma satisfação muito grande. E sem dúvida alguma, procurarei expressar da maneira mais fidedigna, os fatos que tomei conhecimento e que contribui para que se realizassem; e da mesma maneira entrego este depoimento à nossa Universidade Federal de Santa Catarina a fim de que possa servir como documento no futuro para aqueles que querendo retratar a história hoje, colham ali dados e subsídios para estabelecer, juntamente com o depoimento de outras pessoas, estabelecer a verdade dos fatos e o transcorrer da história. (CAMPOS, 1978, p, 1; grifo nosso)

Em que pese a citação suscitar debates sobre as práticas e os usos da HO no período - questões que retomaremos adiante -, a indicação de Freitas para participar do projeto dos Centros Regionais de História Oral ganhou colorações locais específicas.

Após retornar do curso oferecido na UFSC, Freitas relatou ao Colegiado do Departamento de Ciências Sociais da FFCLJ que havia feito mais duas entrevistas orais e que, no próximo ano, com o pleno funcionamento do Centro Regional de História Oral, realizaria entrevistas com todos os ex-prefeitos de Joinville. Entretanto, os planos poderiam ser frustrados, pois mesmo tendo recebido dois gravadores eletrônicos, faltavam outros materiais prometidos, sobretudo as fitas magnéticas para gravação, bem como recursos internos para a contratação de serviços e adequação do espaço de tratamento e disponibilização das fontes produzidas (Cf. FACULDADE DE FILOSOFIA, CIÊNCIAS E LETRAS DE JOINVILLE, Atas No. 33, 1980, p. 37; No. 35, 1980, p. 40; No. 37, 1980, p. 43; No. 43, 1981, p. 48).

Em um texto recentemente publicado, a diretora-geral da FURJ de 1979 a 1982, Lúcia Margarida Currlin Japp, salienta que a Instituição passava por problemas que deveriam ser superados, em especial, a dependência de professores que vinham de

\footnotetext{
${ }^{18}$ Não foram localizados documentos acerca da realização desse curso de pós-graduação em Joinville. De acordo com a professora Dúnia, o curso mencionado pelo entrevistado é, na verdade, a capacitação ministrada por Corrêa. Dúnia contou, ainda, que teria ficado entusiasmada com a possibilidade de abrir um Laboratório de História Oral na FURJ, em cooperação com a UFSC.
} 
iniciou um programa de estímulo para que os docentes locais realizassem cursos de especialização, mestrado e doutorado tanto para cumprir as exigências de credenciamento permanente junto ao Conselho Estadual de Educação de Santa Catarina, como para submeter aos órgãos competentes o projeto para implantar a Universidade da Região Norte-Catarinense. Quanto ao segundo problema, começou a desenvolver o Projeto FURJ-Comunidade, elaborado por professores atuantes em várias áreas de conhecimento na instituição (JAPP, 2015).

No documento "A nova e a velha universidade", espécie de manifesto preliminar do aludido Projeto, são destacados os pontos críticos enfrentados pelas "universidades pequenas do Brasil" durante a década de 1970: "pobreza de recursos financeiros; divórcio dos seus objetivos com respeito aos problemas que afligem as comunidades onde se situam; fraca capacidade de pesquisa; quase nenhuma capacidade de criação de ideias em proveito das comunidades onde se inserem" (FUNDAÇÃO EDUCACIONAL DA REGIÃO DE JOINVILLE, 1982a, p. 1).

Visando proteger "o patrimônio cultural e econômico de Joinville e região" e superar a "tendência centralizadora e mimetista do sistema político e econômico, desfigurando o passado de participação comunitária já existente", o Projeto FURJComunidade previa três grandes frentes de atuação pública: desenvolvimento cultural, melhoria da educação básica e superação da crise econômica que estava afetando a "saúde financeira da comunidade" (indústria, comércio, prefeitura municipal e a própria Furj) (FUNDAÇÃO EDUCACIONAL DA REGIÃO DE JOINVILLE, 1982b, p. 1).

No âmbito desse Projeto, as professoras Dúnia Anjos de Freitas e Eneida Raquel S. Thiago, foram incumbidas de elaborar e executar o denominado "Sub-Projeto A Cultural”. A citação abaixo sinaliza tanto a tática utilizada pelas professoras para dar visibilidade à História Oral em âmbito institucional, quanto às expectativas depositadas no seu uso e disseminação: 
A memória histórica da cidade precisa ser, não somente mantida, mas inserida no espírito do cidadão, promovendo sua continuidade. Contudo, as instalações do atual Arquivo Histórico Municipal não apresentam as mínimas condições de preservação, organização ou uso do acervo. A par disto, a comunidade joinvilense vem se pronunciando constantemente acerca do "problema" Arquivo Histórico. Somado a este problema, é grave a carência de registros documentais das tradições, uso e costumes locais, de fontes escritas que forneçam dados para a pesquisa histórica contemporânea. (FUNDAÇÃO EDUCACIONAL DA REGIÃO DE JOINVILLE, 1982c, p. 4)

Dessa perspectiva, para que a FURJ pudesse cumprir o papel de "preservação e comunicação da cultura" e "proporcionar à comunidade a preservação e continuidade de sua memória histórica", as professoras propunham a instalação formal do Laboratório de História Oral, já intentada no Projeto Centros Regionais de História Oral, e a “Microfilmagem de periódicos do acervo do Arquivo Público Municipal [Arquivo Histórico de Joinville]” (FUNDAÇÃO EDUCACIONAL DA REGIÃO DE JOINVILLE , 1982c, p. 5).

Surpreendentemente, passados apenas dois meses de execução do Projeto FURJComunidade, as professoras relataram ao Colegiado do Departamento de Ciências Sociais da FFCL que o Laboratório de História Oral já se encontrava em funcionamento e que elas estavam desenvolvendo o Projeto História das Administrações Públicas de Joinville. Além da realização e do tratamento técnico de seis entrevistas, envolveram seus alunos do " 3 ano do curso de História" em pesquisas acerca da biografia dos entrevistados (FUNDAÇÃO EDUCACIONAL DA REGIÃO DE JOINVILLE, 1982d, p. 4).

Quanto à microfilmagem de periódicos do Arquivo Histórico de Joinville, destacaram elas que, finalmente, havia sido assinado o Convênio com a UFSC para Indexação de Documentação Histórica do Município, integrado ao Plano Nacional de Microfilmagens de Periódicos Brasileiros, sob coordenação geral da Fundação Casa de Rui Barbosa, do Rio de Janeiro (FUNDAÇÃO EDUCACIONAL DA REGIÃO DE JOINVILLE, 1982e).

Diante do panorama que apresentamos, podemos compreender como a História do LHO/Univille está imbricada com a História da constituição, desde início da década de 1970, de uma rede de pesquisadores e instituições que foram mobilizados para fomentar a HO no país e, em especial, em Santa Catarina. Cabe-nos, agora, problematizar os 
Como vimos na primeira parte deste artigo, a partir dos anos de 1990, a questão das "novas tecnologias" repercutiu marcantemente nos debates acerca das apropriações públicas do conhecimento histórico produzido nas universidades. Isso também é perceptível nos escritos sobre a HO no decorrer dos anos de 1970 e 1980. Procurando demonstrar a pertinência de fontes orais, Corrêa assinalou em sua dissertação defendida em 1977 na UFSC que "desde que o Homem inventou qualquer tipo de escrita faz-se história e ela é feita justamente por tal fato". Contudo, a sólida relação entre o trabalho historiográfico e a escrita estava sendo ameaçada com a invenção de "novas tecnologias", dentre as quais telefone e máquina datilográfica. Mas não apenas isso. Esse fenômeno estava aliado "à falta de tempo do homem moderno" e ambos ameaçavam o rico acervo de fontes até então disponível ao historiador (CORRÊA, 1977, p. 11).

Para ilustrar a situação, Corrêa lembra que "um presidente de uma Província de médio desenvolvimento no Império brasileiro, raramente assinava mais de dez ofícios diariamente", já que se gastava muito tempo para escrevê-los dentro das formalidades oficiais. Por outro lado, bilhetes, cartas e diários eram bastante frequentes e a preservação destes em muito contribuiu para o trabalho de "reconstituição histórica" do período. Já com o telefone, aparelho revolucionário de comunicação à distância, um governante passou a resolver "todo e qualquer problema que demoraria semanas ou meses se dependesse da comunicação escrita". Além disso, "um assunto que levaria várias páginas manuscritas explicativas, no passado, é hoje, tratado em poucas e frias linhas datilografadas" e não se tem mais produzido "documentos pessoais que forneçam elementos ao historiador que pretende reconstituir este presente não somente através de documentos oficiais" (CORRÊA, 1977, p. 12). Diante dessas perdas inestimáveis, caberia à História Oral produzir fontes históricas para os pesquisadores do futuro.

No LHO/Univille, o mesmo argumento era acionado para demonstrar a pertinência para o desenvolvimento do seu primeiro projeto, História das Administrações Públicas de Joinville. Diziam Freitas e Thiago que se fazia mister entrevistar os ex-prefeitos diante da 

tecnologias" que ameaçavam o futuro das pesquisas históricas, serviam-lhes para conformar, naquele presente, a lamentada falta de documentação escrita. Referimo-nos ao gravador de fita cassete, popularizado no início da década de 1960 e da máquina datilográfica, tecnologias então indispensáveis à prática da HO.

Quanto à preocupação do futuro da pesquisa histórica, à HO era atribuído um papel de destaque, pois, ainda que produzida intencionalmente, era uma fonte que correspondia a "um material virgem para ser utilizado posteriormente" (CORRÊA, 1977, p. 15). Insinua-se nessas palavras de Corrêa o quão era corroborada a crença da importância de imparcialidade e de relativo distanciamento temporal do historiador com seu objeto de pesquisa. A esse respeito, Corrêa, no depoimento que fez a Santhiago, lembrou-se das dificuldades iniciais para convencer as pessoas a cederem entrevistas, especialmente porque se vivia num clima político bastante tenso. Disse ele, "todo mundo ficava com medo de falar! Até que a gente convencesse a pessoa de que não tinha nada de política, não tinha nada de... Mesmo assim foi um problema muito grande" (SANTHIAGO, 2015, p. 230). Contudo, sugere Corrêa que, à medida que a HO foi se consolidando como fonte histórica junto a pesquisadores mais jovens, ela "começou a ser deturpada”. Isso porque teria se tornado um fim de pesquisa e não uma metodologia a ser mobilizada em função de temas e problemas ${ }^{19}$.

As palavras de Corrêa nos remetem às tensas relações entre memória e História emergentes de nossa análise acerca da trajetória do LHO/Univille. Num primeiro momento, a História Oral foi tomada como território próprio dos historiadores. A eles cabiam tanto a produção quanto o uso das fontes orais, pois se supunha que eram os profissionais aptos e credenciados para garantir o estatuto científico da fonte e do que poderia se extrair dela.

\footnotetext{
${ }^{19}$ Consideramos que a afirmação de Corrêa acerca da deturpação da HO também pode estar ligada as suas lembranças sobre os embates, as disputas e os conflitos no campo da historiografia catarinense, os quais vivenciou, ao longo da década de 1990. A esse respeito ver discussão e análise bastante consistente feita por Janice Gonçalves (2006) em sua tese de doutorado.
} 
No decorrer dos anos de 1980, contudo, nos Relatórios de Atividades do LHO/Univille pode-se constatar a atribuição de novos sentidos à $\mathrm{HO}$, tais como o de “valorizar e resgatar a nossa memória” e "auxiliar as populações das comunidades [locais] a manter sua identidade cultural, bem como conscientizá-las da necessidade de preservá-la através de uma atitude participativa" (FUNDAÇÃO EDUCACIONAL DA REGIÃO DE JOINVILLE, 1984, p. 1).

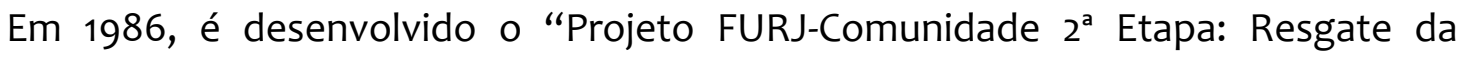
Memória da Imigração Alemã na Região de Joinville", que previa como resultado uma coleção de "Entrevistas gravadas de acordo com a técnica de História Oral” que servisse de material didático para: uso curricular do ensino da $1^{\mathrm{a}}$ a $8^{\mathrm{a}}$ série, "estimular a preservação de monumentos arquitetônicos" e "da arte alemã da região” (FUNDAÇÃo EDUCACIONAL DA REGIÃO DE JOINVILLE, 1986, p. 28). Ainda que o acervo do LHO continuasse a ser enriquecido por meio de investigações vinculadas a dissertações e teses desenvolvidas por historiadores, na sua institucionalidade, o aludido projeto promovia uma espécie de equivalência entre memórias narradas e conhecimento histórico. Além de suscitar equívocos problemáticos do ponto de vista teórico-metodológico, cabe-nos perguntar se tal equivalência não poderia ser tomada como um indício de preocupação e desejo do LHO/Univille, por meio daqueles que estavam a sua frente, ampliar os públicos da $\mathrm{HO}$, bem como responder às novas demandas que se abriam para os historiadores e para a história do presente.

\section{De saída: a História Pública como interface entre a História Oral e o papel público do historiador na escrita da História do Tempo Presente}

Nas páginas anteriores, fizemos um esforço no sentido de demonstrar certas zonas de contato entre a História Pública e a História Oral. Na primeira parte do artigo, analisamos um conjunto de textos sobre a historicidade dos estudos em HP na Inglaterra, nos Estados Unidos e no Brasil. A partir de uma reflexão bibliográfica, procuramos problematizar como a $\mathrm{HO}$ foi mobilizada e articulada nos diferentes contextos de emergência da HP. 
Na sequência, apresentamos uma discussão sobre o processo de constituição de uma rede institucional de espaços voltados à difusão pública de fontes orais, enfocando as maneiras pelas quais a $\mathrm{HO}$ foi sendo apropriada e significada, especialmente em Santa Catarina, a partir dos anos de 1970. Nesse movimento, pudemos nos defrontar com as dificuldades de aproximar a HO e a HP.

Para nós, investigar a história do LHO/Univille foi uma oportunidade para refletir sobre os diferentes sentidos atribuídos ao ofício de historiador. Nesse âmbito, problematizamos as expectativas de diferentes projetos que, durante os anos 1980, à sua maneira, previram a mediação do historiador no processo de elaboração de fontes orais de pesquisa por meio de interação com a sociedade.

De saída, cumpre dizer que vislumbramos a HP como interface entre a promoção reflexiva da $\mathrm{HO}$ e o papel público do historiador na escrita da História do Tempo Presente (HTP). Aqui, não se trata de, mais uma vez, passar em relevo outros de nossos estudos nos quais aproximamos HO e HTP (SOSSAI E MENDES, 2016; COELHO E SOSSAI, 2015; COELHO, SOSSAI E MACHADO, 2014; SOSSAI E COELHO, 2011). Trata-se, sim, de enfatizar que entendemos a HP como uma possibilidade a todo historiador interessado em investigar a historicidade de seu tempo.

Além disso, ao defendermos que a HP pode figurar como interface entre a $\mathrm{HO}$ e a ação pública do historiador na HTP, estamos também propondo que a História Pública é um caminho para o enfrentamento de complexas questões contemporâneas que exigem dos historiadores um efetivo posicionamento, em especial: os usos mercadológicos do passado em diferentes plataformas digitais (history business); as tensões envolvidas com a regulamentação da profissão de historiador no Brasil (as disposições do Projeto de Lei Federal No. 4699/2012); os conflitos emergentes das disputas públicas pela memória social e pelo patrimônio cultural... Enfim, um vasto conjunto de desafios aos quais a HP vem dedicando atenção e que se forem sintonizados aos estudos em HTP todos que atuam no campo da História sairiam ganhando.

Nessa direção, cremos não ser equivocado afirmar que a HP é uma perspectiva que tem vivamente estimulado os historiadores a levar em conta as múltiplas expressões 
abordagens interdisciplinares em História (como a HO). Entre outros, na HP, busca-se lembrar os próprios historiadores que a sociedade pode ter por base desejos de saber em História que nem sempre possuem um filamento acadêmico em seu DNA. Desse ponto de vista, a HP propõe mover as fronteiras do campo da História para que abranja territórios públicos que hoje são pouco explorados pelos historiadores. Quem sabe esse deslocamento possa nos conduzir a uma maior valorização do ofício de historiador nas sociedades do presente, bem como dos produtos resultantes de seu trabalho. Quer dizer, leve-nos a uma ampliação dos públicos da História, do conhecimento histórico.

\section{Agradecimentos}

Gostaríamos de manifestar nossos agradecimentos às pessoas que generosamente nos ajudaram a produzir este artigo. À professora Dúnia Anjos de Freitas pelas informações prestadas, as quais exigiram de sua parte muita paciência em responder as dúvidas lacunares que iam surgindo à medida que analisávamos as fontes, e pelo esforço em "puxar" lembranças quase adormecidas sobre a sua trajetória profissional. À Katia Oliari da Motta, coordenadora do Arquivo Central da Univille, Beatriz Rengel e Ketlyn Cristina Alves, bolsistas do Laboratório de História Oral e do Centro Memorial da Univille, pela garimpagem da documentação nos acervos desses espaços, muitos ainda em fase de processamento técnico. E, por fim, ao historiador Diego Finder Machado pelas discussões e leitura de versões preliminares deste artigo. 


\section{Referências}

ASSOCIAÇÃO BRASILEIRA DE HISTÓRIA ORAL. [Site]. Disponível em: <http://www.historiaoral.org.br/>. 21 set. 2016.

ASSOCIAÇÃO BRASILEIRA DE HISTÓRIA ORAL. Apresentação. 2016. Disponível em: <http://www.historiaoral.org.br/conteudo/view?ID_CONTEUDO=24>. Acesso em: 20 nov. 2016.

ASSOCIAÇÃO CATARINENSE DAS FUNDAÇÕES EDUCACIONAIS. ACAFE-Memória: 19742014. 2014. Disponível em: <http://www.new.acafe.org.br/acafe/acafe>. Acesso em: 10 set. 2016.

ASSOCIAÇÃO CATARINENSE DAS FUNDAÇÕES EDUCACIONAIS. Ofício 1448/80, enviado por Lauro Ribas Zimmer para Lúcia Margarida Currlin Japp. Florianópolis, 30 de julho de 1980. Acervo do Laboratório de História Oral da Univille.

BRASIL. Ministério da Educação e Cultura. Universidade Federal de Santa Catarina. Centro de Ciências Humanas. Curso de Pós-graduação em História. Programa Piloto para a criação de Centros Regionais de História Oral de Santa Catarina-BRASIL. Florianópolis, 06 de abril de 1980. Acervo do Laboratório de História Oral da Univille.

BRASIL. Senado Federal. Projeto de Lei 4699/2012, de autoria do Senador Paulo Paim. Brasília, 2012. Apresentado em 12 de novembro de 2012.. Acervo do Centro Memorial da Univille.

BRASIL. Serviço Público Federal. Ministério da Educação e Cultura. Ofício MEC/SEG/SEAI/CODAM, enviado por Pedro Demo a Walter F. Piazza. Brasília, 1980. Acervo do Laboratório de História Oral da Univille.

CAMPOS, Pedro Ivo. Entrevista oral concedida à professora Dúnia Anjos de Freitas: transcrição. Joinville, 21 de julho de 1978. Acervo do Laboratório de História Oral da Univille.

CHALHOUB, Sidney; FONTES, Paulo. História social do trabalho, história pública. Perseu, v. 4, p. 218-228, 2009.

GONÇALVES, Janice. Sombrios umbrais a transpor: arquivos e historiografia em Santa Catarina no século XX. 2006, 444f. Tese (Doutorado em História) - Universidade de São Paulo-USP . Programa de Pós-graduação em História Social, São Paulo, 2006. 
COELHO, Ilanil. Univille: uma escrita histórica. In: COELHO, Ilanil; SOSSAI, Fernando Cesar (Orgs.). Univille: 50 anos de ensino superior em Joinville e região (1965-2015). Joinville: Editora da Univille, 2015. p. 27-64.

COELHO, Ilanil; SOSSAI, Fernando Cesar (Orgs.). Univille: 50 anos de ensino superior em Joinville e região (1965-2015). Joinville: Editora da Univille, 2015.

COELHO, Ilanil; SOSSAI, Fernando Cesar; MACHADO, Diego Finder. História oral, cidade e lazer no tempo presente. História Oral, v. 17, p. 7-37, 2014.

CORRÊA, Carlos Humberto Pederneiras. O documento de História Oral como fonte histórica: uma experiência brasileira. 1977. Dissertação (Mestrado em História) Universidade Federal de Santa Catarina. Programa de Pós-graduação em História. Florianópolis, 1977.

DANNIAU, Fien. Public History in a digital context: back to the future or back to basics? Bmgn-Low Countries Historical Review, v. 128-4, p. 118-144, 2013.

DAVISON, Graeme. Paradigms of public history. Australian Historical Studies, v. 24, issue 96, p. 4-15, 1991.

DE ALMEIDA, Juniele Rabêlo. Práticas de história pública: o movimento social e o trabalho de história oral. In: ALMEIDA, Juniele Rabêlo; MAUAD, Ana Maria; SANTHIAGO, Ricardo. (Orgs.). História pública no Brasil: sentidos e itinerários. São Paulo: Letra e Voz, 2016. p. 47-56.

DE ALMEIDA, Juniele Rabêlo; ROVAI, Marta Gouveia de Oliveira. História pública: entre as "políticas públicas" e os "públicos da história”. Anais do XXVII Simpósio Nacional de História da ANPUH: conhecimento histórico e diálogo social. Natal: ANPUH, 2013. p. 1-10.

DOUGLASS, Enid H. Oral History and Public History. The Oral History Review, v. 8, p. 1-5, 1980.

EVANGELISTA, Marcela Boni; ROVAI, Marta Gouveia de Oliveira; RIBEIRO, Suzana Lopes Salgado. Audiovisual e história oral: utilização [de] novas tecnologias em busca de uma história pública. Oralidade, v. 5, n. 10, p. 89-105, 2011.

FACULDADE DE FILOSOFIA, CIÊNCIAS E LETRAS DE JOINVILLE. Departamento de Ciências Sociais. Ata No. 5: Joinville, 29 de março de 1971. Acervo do Arquivo Central da Univille.

FACULDADE DE FILOSOFIA, CIÊNCIAS E LETRAS DE JOINVILLE. Departamento de Ciências Sociais. Ata No 33: Joinville, 12 de agosto de 1980. Acervo do Arquivo Central da Univille. 
FACULDADE DE FILOSOFIA, CIÊNCIAS E LETRAS DE JOINVILLE. Departamento de Ciências Sociais. Ata No 35: Joinville, 02 de outubro de 1980. Acervo do Arquivo Central da Univille.

FACULDADE DE FILOSOFIA, CIÊNCIAS E LETRAS DE JOINVILLE. Departamento de Ciências Sociais. Ata No 37: Joinville, 02 de dezembro de 1980. Acervo do Arquivo Central da Univille.

FACULDADE DE FILOSOFIA, CIÊNCIAS E LETRAS DE JOINVILLE. Departamento de Ciências Sociais. Ata No 43: Joinville, 17 de setembro de 1981. Acervo do Arquivo Central da Univille.

FONSECA, Thaís Nívia de Lima. Mídias e divulgação do conhecimento histórico. Aedos, v. 4, n. 11, p. 129-140, set. 2012.

FUNDAÇÃO EDUCACIONAL DA REGIÃO DE JOINVILLE. A nova e a velha universidade: o Projeto FURJ-Comunidade em Joinville. Joinville, 1982a. Acervo do Arquivo Central da Univille.

FUNDAÇÃO EDUCACIONAL DA REGIÃO DE JOINVILLE. Projeto FURJ-Comunidade: objetivo e conteúdo. Joinville, 1982b. Acervo do Arquivo Central da Univille.

FUNDAÇÃO EDUCACIONAL DA REGIÃO DE JOINVILLE. Projeto FURJ-Comunidade: SubProjeto A - Cultural. Joinville, 1982c. Acervo do Arquivo Central da Univille.

FUNDAÇÃO EDUCACIONAL DA REGIÃO DE JOINVILLE. Projeto FURJ-Comunidade $\mathbf{2}^{\mathbf{a}}$ Etapa: resgate da memória da imigração alemã na Região de Joinville. Joinville, 1986. Acervo do Arquivo Central da Univille.

FUNDAÇÃO EDUCACIONAL DA REGIÃO DE JOINVILLE. Relatório do Projeto FURJComunidade: Sub-Projeto A - Cultural. Joinville, 28 de outubro de 1982d. Acervo do Arquivo Central da Univille.

FUNDAÇÃO EDUCACIONAL DA REGIÃO DE JOINVILLE. Relatório do Projeto FURJComunidade: Sub-Projeto A - Cultural. Joinville, 1984. Acervo do Arquivo Central da Univille.

FUNDAÇÃO EDUCACIONAL DA REGIÃO DE JOINVILLE. Termo de Convênio que entre si celebram a Fundação Educacional da Região de Joinville-FURJ, a Prefeitura Municipal de Joinville e a Universidade Federal de Santa Catarina-UFSC, visando a execução do SubProjeto "C" do Projeto FURJ-Comunidade. Joinville, agosto de 1982e. Acervo do Arquivo Central da Univille. 
HALL, Stuart. Raphael Samuel: 1934-1996. New Left Review, v. 1, n. 221, p. 119-127, jan.-feb. 1997.

HISTORY WORKSHOP ONLINE. [Site]. Disponível em:

<http://www.historyworkshop.org.uk>. Acesso em: 21 set. 2016.

INDIANA UNIVERSITY. Ruth Lilly Special Collections \& Archive. National Council on Public History Records, 1977-2002. Historical note NCPH. Last update 20 jan. 2016. Disponível em: <http://www.ulib.iupui.edu/collections/general/mss021>. Acesso em: 15 set. 2016.

JAPP, Lúcia Margarida. Lúcia Margarida Currlin Japp - diretora-geral da FURJ, período 1979-1982. In: COELHO, I.; SOSSAI, F. C. (Orgs.). Univille: 50 anos de ensino superior em Joinville e região (1965-2015). Joinville: Editora da Univille, 2015. p. 100-102.

JOHNSON, George Wesley. Entrevista oral concedida a Phillip V. Scarpino. 98min.

English. Asheville, Tennessee. 17 abr. 2015. Disponível em:

<https://archives.iupui.edu/handle/2450/10801?show=full>. Acesso: 10 set. 2016.

JORDAN, Grant. The British administrative system: principles versus practice. London: Routledge, 2005.

KEAN, Hilda. Public history and Raphael Samuel: a forgotten radical pedagogy? Public History Review, n. 11, p. 51-62, 2004.

LABORATÓRIO de História Oral da Univille. [Site]. Disponível em: <http://houniville.wixsite.com/novo>. Acesso em: 21 set. 2016.

LABORATÓRIO DE HISTÓRIA ORAL DA UNIVILLE. Acervo. Joinville, 2016. Disponível em: <http://lhouniville.wixsite.com/novo/acervo>. Acesso em: 15 set. 2016.

LIDDINGTON, Jill. O que é história pública?: os públicos e seus passados. In: DE ALMEIDA, Juniele Rabêlo; ROVAI, Marta Gouveia de Oliveira (Orgs.). Introdução à História Pública. Rio de Janeiro: Letra e Voz, 2011. p. 31-52.

LUCCHESI, Anita. Conversas na antessala da academia: o presente, a oralidade e a história pública digital. História Oral, v. 17, n. 1, p. 39-69, jan./jun. 2014.

MA in Public History, Ruskin College. [Site]. Disponível em:

<https://www.ruskin.ac.uk/perch/resources/mapublichistoryfactsheet.pdf $>$. Acesso em: 21 set. 2016.

MAUAD, Ana Maria; DE ALMEIDA, Juniele Rabêlo; SANTHIAGO, Ricardo (Orgs.). História pública no Brasil: sentidos e itinerários. São Paulo: Letra e Voz, 2016. 
MEIHY, José Carlos Bom. Canto de morte Kaiowá: história oral de vida. São Paulo: Edições Loyola, 1991.

NATIONAL COUNCIL ON PUBLIC HISTORY. [Site]. Disponível em: <http://ncph.org>. Acesso em: 21 set. 2016.

NOIRET, Serge. Historia digital y historia pública. In: BRESCIANO, Juan Andrés.; GIL, Tiago. (Comp.). La historiografía ante el giro digital: reflexiones teóricas y prácticas metodológicas. Montevideo: Ediciones Cruz del Sur, 2015b. p. 41-76.

NOIRET, Serge. História Pública digital. Liinc em Revista. Rio de Janeiro, v. 11, n. 1, p. 28-51, maio, 2015a.

NOIRET, Serge. Internationalizing Public History. Public History Weekly, n. 2, p. 1-9, 2014.

PIAZZA, Walter Fernando. A Pesquisa Histórica em Santa Catarina. Revista de Ciências Humanas, v. 1, n. 1, p. 102-107, 1982.

REDE BRASILEIRA DE HISTÓRIA PÚBLICA. [Site]. Disponível em: <http://historiapublica.com.br>. Acesso em: 21 set. 2016.

REDE BRASILEIRA DE HISTÓRIA PÚBLICA. Carta de Fundação. Belo Horizonte, 25 set. 2012. Disponível em: <http://historiapublica.com.br/?page_id=520>. Acesso: 20 mai. 2016.

RITCHIE, Donald A. Doing Oral History: a practical guide - using interviews to uncover the past and preserve it for the future. 2 ed. New York: Oxford University Press, 2003.

SAMUEL, Raphael. Local history and Oral History. History Workshop Journal, n. 1, p. 191208, Spring 1976.

SANTHIAGO, Ricardo. A História Pública é a institucionalização de um espírito que muitos historiadores têm tido, por milhares de anos: uma entrevista com David King Dunaway sobre História Oral, História Pública e o passado nas mídias. Revista Transversos. Rio de Janeiro, v. 7, n. 7, p. 203-222, set. 2016. Disponível em: <http://www.epublicacoes.uerj.br/index.php/transversos>. Acesso em: 19 nov. 2016.

SANTHIAGO, Ricardo. Carlos Humberto Pederneiras Corrêa, um pioneiro da história oral no Brasil. História Oral, v. 18, n. 1, p. 221-239, jan./jun. 2015.

SANTHIAGO, Ricardo. Palavras no tempo e no espaço: a gravação e o texto de história oral. In: DE ALMEIDA, J. R.; ROVAI, M. G. de Oliveira (Orgs.). Introdução à história pública. Rio de Janeiro: Letra e Voz, 2011. p. 97-108. 
SCHÜTZ, Karla Simone Willemann. Lembranças revisitadas: o laboratório de história oral da UFSC e as entrevistas de Simão Willemann - memória e história oral em Santa Catarina (1975-2013). 2015. Dissertação (Mestrado em História) - Universidade do Estado de Santa Catarina Programa de Pós-graduação em História, Florianópolis, 2015.

SIMPÓSIO INTERNACIONAL DE HISTÓRIA PÚBLICA: a história e seus públicos, São Paulo, 16-20 jun. de 2012. Textos completos. São Paulo: Rede Brasileira de História Pública, 2012. Disponível em: <https://redebrasileiradehistoriapublica.files.wordpress.com/2013/01/ahistc3b3ria-e-seus-pc3bablicos-_-anais.pdf>. Acesso em: 10 set. 2016.

SIMPÓSIO INTERNACIONAL DE HISTÓRIA PÚBLICA: perspectivas da história pública no Brasil, 2º Niterói, 10-12 set. 2014. Quadro de programação. Niterói: Universidade Federal Fluminense, 2012. Disponível em:

<http://historiapublica.com.br/simposio2014/?page_id=74>. Acesso em: 10 set. 2016.

SOSSAI, Fernando Cesar; COELHO, Ilanil. Memórias do Jardim Sofia: cenas da cidade migrante. Joinville: Editora da Univille, 2011.

SOSSAI, Fernando Cesar; COELHO, Ilanil. Procedimento Operacional Padrão do Laboratório de História Oral da Univille. Joinville, 2014. Mimeo. Acervo do Laboratório de História Oral da Univille.

SOSSAI, Fernando Cesar; MENDES, Geovana. Tempo tecnológico: uma análise de narrativas orais sobre o uso de tecnologias digitais em escolas públicas de Santa Catarina. História Oral, v. 19, n. 1, p. 7-39, jan./jun. 2016.

THOMPSON, Edward Palmer. The making of the English working class. Oxford: Pelican Book, 1963.

UNIVERSIDADE FEDERAL DE SANTA CATARINA. Centro de Ciências Humanas. Curso de Pós-graduação em História. Ofício No. 157/80, enviado por Walter F. Piazza a Silvio Coelho dos Santos. Florianópolis, 18 de junho de 1980. Acervo do Centro Memorial da Univille.

URIBE, Daniel; COELHO, Ilanil. Mercados Campesinos in Bogotá: Cultural heritage policies in Colombia regarding the constructions of sustainability instruments for the rural communities' knowledge and practices. In: 3rd INTERNATIONAL PUBLIC HISTORY ANNUAL CONFERENCE (IFPH). Bogotá: Universidad de los Andes, July 7-9, 2016.

VIANNA, Marcelo. Repensando memórias como fontes para história pública - uma visão sobre depoimentos de antigos membros do Ministério Público do Rio Grande do Sul.

Oficina do Historiador, v. 6, n. 2, p. 41-56, jul./dez. 2013. 
Recebido em 01/10/2016 Aprovado em 16/11/2016

Universidade do Estado de Santa Catarina - UDESC Programa de Pós-Graduação em História - PPGH

Revista Tempo e Argumento Volume 08 - Número 19 - Ano 2016 tempoeargumento@gmail.com 